\title{
Clinical and immunological reactions to Aspergillus niger among workers at a biotechnology plant
}

\author{
M D TOPPING, ${ }^{1}$ D A SCARISBRICK, ${ }^{2}$ C M LUCZYNSKA, ${ }^{\prime}$ E C CLARKE, ${ }^{2}$ AND \\ A SEATON ${ }^{3}$ \\ From the Health and Safety Executive, ${ }^{1}$ London, Employment Medical Advisory Service, ${ }^{2}$ Leeds, and \\ Institute of Occupational Medicine, ${ }^{3}$ Edinburgh, UK
}

ABSTRACT The workforce at a biotechnology plant producing citric acid by fermentation of molasses with a strain of Aspergillus niger was studied. A combination of a respiratory questionnaire and clinical assessment identified 18 subjects $(4.9 \%$ of the workforce) with work related bronchospasm. In nine of these evidence of sensitisation to $A$ niger was obtained by skin prick tests and radioallergosorbent test (RAST) using as an antigen an extract of the $\boldsymbol{A}$ niger culture fluid from the process. Of the 325 subjects without work related bronchospasm, only nine $(2 \cdot 7 \%)$ had a positive prick test. There were no subjects with symptoms of extrinsic allergic alveolitis. Investigation into the source of the antigen showed that whereas, in some areas of the plant, $A$ niger spores were present, in others there were no detectable spores. In these areas, however, extracts of filters from air samplers were shown by RAST inhibition to contain $A$ niger antigens, indicating that the culture fluid was generating airborne antigen. RAST inhibition studies showed that the $A$ niger culture fluid used in the process contained antigens that were not present in a commercially available $A$ niger extract, thus emphasising the importance in this type of investigation of using antigens prepared from material to which the workers are exposed.

Micro-organisms have been used in the production of food for many centuries; the Egyptians discovered around $4000 \mathrm{BC}$ that the carbon dioxide generated by the action of brewer's yeast could leaven bread, and the ability of yeast to make alcohol in the form of beer was known before that. Nevertheless, it is only within the past 50 years that micro-organisms have been extensively used in the synthesis of chemicals on an industrial scale. The development of genetic engineering has resulted in further rapid growth in the application of micro-organisms to industrial processes and more than 40 microorganisms, including species of yeasts, fungi, and bacteria, are now used in the production of products such as food, chemicals, vitamins, enzymes, and pharmaceuticals.'

One of the potential hazards of these processes is the sensitisation of workers to airborne microorganisms and culture fluid material which may result in either extrinsic allergic alveolitis or asthma. Several fungal species have been identified as causes

(C) Crown Copyright 1984.

Received 16 July 1984

Accepted 17 September 1984 of occupational asthma. For example, extracts of $\stackrel{\circ}{3}$ Cladosporium, Verticillium, and Paecilomyces species gave immediate skin prick test reactions and, on inhalation, a fall in FEV in farmers engaged in harvesting. ${ }^{2}$ Klaustermeyer et al reported cases of two bakers, one of whom had a positive bronchial challenge to Aspergillus species and the other a positive response to Alternaria species. ${ }^{3}$ At least one Aspergillus species, $A$ fumigatus, has been recognised as a cause of respiratory disease in farm workers exposed to mouldy hay contaminated by spores. This is a form of extrinsic allergic alveolitis but is said to differ from classical farmers' lung in that those affected usually have a history of asthma, and $\widetilde{\sigma}$ that the attacks develop more rapidly and are $N$ characterised by wheezing and evidence of both $N$ immediate and late skin responses to extracts of $A$ fumigatus. ${ }^{4}$ Similarly, workers at a cane sugar mill have both immediate and late skin test reactions to A fumigatus. ${ }^{5}$

The spore of Aspergillus niger may be found in the air at an average concentration of less than 5 per $\mathrm{m}^{3}$. Nevertheless, it may not infrequently be cultured from human lung or sputum, indicating that it shares with $A$ fumigatus the ability to resist the human 
lung's defences. ${ }^{6}$ It has rarely been implicated in disease but may in appropriate circumstances cause otitis externa, allergic alveolitis, invasive aspergillosis, aspergilloma (sometimes producing oxalic acid $^{7}$ ) and endocarditis after open heart surgery. ${ }^{8}$ To our knowledge, it has not previously been described as a cause of occupational asthma.

The present paper describes an investigation at a biotechnology plant where one worker was diagnosed as having occupational asthma (index case) and where, in addition, preliminary inquiries indicated that several other employees had work related respiratory symptoms. The main process at the factory is the production of citric acid by the fermentation of molasses with a specially selected strain of $\boldsymbol{A}$ niger. The fermentation is carried out either by a "surface method," in which stainless steel trays are arranged in racks in cells, filled with molasses, the cells closed, and $A$ niger spores blown in; or by "deep fermentation" in large enclosed tanks that are filled with a dilute preparation of molasses, stirred, "spurged" with air, and $A$ niger spores introduced. Fermentation takes place under controlled conditions and when it is complete the culture fluid goes to the second stage for the recovery of the citric acid which takes place in a separate enclosed building. The citric acid is precipitated from the culture fluid by the addition of calcium hydroxide, to form calcium citrate, which is then purified by a technique of counter current washing. During the washing procdure the washing water passes through the slurry three times. Citric acid is recovered from the slurry by the addition of sulphuric acid, which leaves the citric acid in solution and precipitates hydrated calcium sulphate (gypsum). In the final stage the citric acid is crystallised, centrifuged, dried, and packed for despatch.

In 1975 an employee who had worked on the recovery process for 10 years began to experience episodes of chest tightness and wheezing that led to periods of sickness absence and which increased in frequency and severity. He noticed that they were related to his work pattern, and in 1982 a chest physician diagnosed "occupational asthma". While the work reported here was in progress this man (the "index" case) became so disabled by attacks of asthma precipitated by his work (although he was symptom free away from work) that a change of job was advised. He transferred to the citric acid drying and packing area, with good effect, suffering many fewer attacks of asthma.

An examination of the production process suggested that $\boldsymbol{A}$ niger was the most likely cause of respiratory symptoms at the plant. The survey reported here was undertaken to establish the prevalence of work related respiratory symptoms among the work force and the correlation between symptoms and sensitisation to $A$ niger as determined by radioallergosorbent test (RAST) and skin prick test. In addition, RAST inhibition was used to detect airborne $A$ niger antigen.

\section{Materials and methods}

\section{SUBJECTS}

Altogether 365 workers were employed full time at the factory; this included management, staff, process operators, and laboratory personnel. At the time of our investigation $343(94 \%)$ were present at the plant, (the others being absent either on business or on sick leave); all answered a questionnaire and were skin prick tested. Blood was taken from a selected subgroup, those with work related symptoms and case matched controls, the serum being separated and stored at $-20^{\circ} \mathrm{C}$ until assayed.

\section{CLINICAL ASSESSMENT}

The first phase of the clinical assessment consisted of the administration of the MRC respiratory symptoms questionnaire that was modified by simplifying the questions on smoking, and by the addition of questions on the keeping of birds and farming.

In the second phase subjects were placed into three groups on the basis of their answers to the questionnaire: those with no respiratory symptoms; those with respiratory symptoms, but not chest tightness, wheeziness or " asthma"; and those whose answers to the questionnaire indicated chest tightness or wheeziness, or both. All those in this last group were assessed clinically and placed in one of three further groups: those whose symptoms were either not clinically important or not related to their occupation; those whose symptoms were occupationally related, but which suggested direct bronchial irritation rather than sensitisation; and, finally, those whose symptoms suggested a diagnosis of occupational asthma.

\section{PREPARATION OF ANTIGENS \\ From A niger culture ftuid}

One litre of $\boldsymbol{A}$ niger culture fluid, taken after culture and just before the recovery of citric acid, was dialysed extensively against running tap water at room temperature and then freeze dried. The freeze dried material was reconstituted in $300 \mathrm{ml}$ of $0.02 M$ ammonium bicarbonate, centrifuged, dialysed against $0.02 \mathrm{M}$ ammonium bicarbonate at $4^{\circ} \mathrm{C}$, and refreeze dried. The final freeze dried extract weighed $4.04 \mathrm{~g}$ and contained $2.5 \%$ protein. 


\section{From counter current washing water}

One litre of wash water collected from the final spray nozzle was freeze dried, reconstituted in $100 \mathrm{ml}$ of $0.02 M$ ammonium bicarbonate, then dialysed against $0.02 M$ ammonium bicarbonate at $4^{\circ} \mathrm{C}$. After centrifugation and refreeze drying the extract weighed $1.037 \mathrm{~g}$ and contained $4.6 \%$ protein.

\section{From air samples}

Two Staplex samplers were run for 17 hours at $1600 \mathrm{l} / \mathrm{min}$ at two sites in the stage 2 area of the plant, near the counter current washing, and were coded A and B. The filters were weighed before insertion in the Staplex and again as soon as they reached the laboratory in order to give the total dry weight on the filter. Each was then placed in a blender with 11 of $0.02 M$ ammonium bicarbonate and macerated for $30 \mathrm{~s}$; the resultant pulp was allowed to stand overnight at $4^{\circ} \mathrm{C}$. Filter debris was removed by filtration through a sintered glass filter and the filtrate was freeze dried. The freeze dried material was reconstituted in $25 \mathrm{ml}$ of phosphate buffered saline, centrifuged, dialysed against $0.02 M$ ammonium bicarbonate, and refreeze dried. The freeze dried extracts were reconstituted in a minimum volume of phosphate buffered saline ( $5 \mathrm{ml}$, filter A; $1 \mathrm{ml}$ filter B) and stored at $-20^{\circ} \mathrm{C}$ until used.

\section{PROTEIN DETERMINATION}

The protein content of the antigen extracts was determined by the method of Bradford" using a Cobas Bio autoanalyser. A freeze dried human serum (Sero-norm protein; Nygaard, Oslo, Norway) was used as a standard.

\section{SKIN PRICK TESTS}

$A$ niger culture fluid extract was dissolved in Coca's solution (0.03 $M$ sodium bicarbonate, $0.086 M$ sodium chloride, $0.4 \%$ phenol) to give a $2 \% \mathrm{w} / \mathrm{v}$ solution. Then, under a stream of sterile air, $2.5 \mathrm{ml}$ was passed through a $0.22 \mu \mathrm{m}$ Millex filter (Millipore Ltd) into $2.5 \mathrm{ml}$ of sterile glycerol containing $0.4 \%$ phenol, to give a $1 \% \mathrm{w} / \mathrm{v}$ prick test solution. Skin prick test solutions of $\boldsymbol{A}$ niger and $\boldsymbol{A}$ fumigatus were purchased from Bencard, and a $0.5 \%$ histamine solution from E Merck Ltd. Skin prick tests were performed on the forearm of each subject. Coca's solution containing $50 \%$ glycerol was used as a negative control, and a positive reaction was defined as a weal at 10 minutes of $2 \mathrm{~mm}$ diameter after subtracting any reaction to the control solution; $0.5 \%$ histamine was used as a positive control.
MEASUREMENT OF SPECIFIC IGE ANTIBODY

Specific IgE was measured by RAST. Extracts were coupled to paper discs activated with cyanogen bromide $^{10}$ using, per $100 \mathrm{mg}$ of activated discs, the following concentrations of allergen extract: $A$ niger culture fluid extract, $10 \mathrm{mg}$; extract from filter $A, \frac{\bar{D}}{\bar{c}}$ $330 \mu \mathrm{l}$; and Bencard $A$ niger and $A$ fumigatus prick $\frac{\widehat{\sigma}}{\overparen{D}}$ test extracts, $400 \mu$ l. Allergen specific IgE in serum $\cong$ samples was determined by incubating $200 \mu$ l of a is $1: 4$ dilution of serum with an allergen disc overnight $\overrightarrow{0}$ at room temperature. After washing the disc, bound IgE was detected by a further overnight incubation $\vec{\omega}$ at room temperature with $50 \mu \mathrm{l}$ of ${ }^{125}$ I labelled anti- $\bigcirc$ human IgE (Pharmacia, Uppsala, Sweden). After $\stackrel{\mathbb{D}}{\mathcal{D}}$ removal of unbound ${ }^{125} \mathrm{I}$, the ${ }^{125} \mathrm{I}$ bound to the disc was measured with an LKB rackgamma II counter. All assays were performed in duplicate and the $\stackrel{\sigma}{\omega}$ results expressed as mean percent counts bound to $\frac{\omega}{N}$ the disc.

\section{RAST INHIBITION}

RAST inhibition was performed by a method developed from that of Yman et al. " Briefly this was as follows; aliquots of a dilution of a serum with high $\stackrel{\infty}{\infty}$ IgE concentration to the $A$ niger culture fluid extract $O$ were mixed with increasing amounts of soluble phase allergen, then a solid phase allergen disc added, and the IgE bound to the disc measured in the same way as described above. The results were expressed as the percentage inhibition resulting $\mathscr{\perp}$ from the addition of the soluble phase allergen.

\section{Results}

\section{CLINICAL FINDINGS}

Of the 343 workers who completed questionnaires, 201 had no symptoms (group A) and 36 complained of chest symptoms but not of chest tightness, 3 wheeze, or asthma (group B). The remaining 106 people indicated on the questionnaire that they had experienced tightness of the chest or wheeze. These subjects were examined and an assessment made of $\stackrel{\circ}{\longrightarrow}$ the significance of their symptoms. It was concluded $\frac{D}{O}$ that in 64 cases (group C) the symptoms were either of no clinical importance or not related to occupa- No tion. Of the remainder, in 24 subjects (group D) the symptoms were occupationally related, but clinical ${ }_{N}$ assessment did not suggest episodes of airways obs- $\omega$ truction. In general it was concluded that the symptoms in this group were due to direct irritation of the upper respiratory tract and were associated with exposure to citric acid dust in the drying and packing ? areas. In the remaining 18 cases it was concluded 0 that occupational asthma could be diagnosed on $\stackrel{\vec{D}}{\mathbb{D}}$

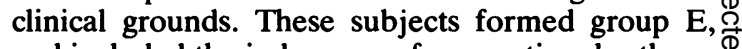
and included the index case of occupational asthma. $\varrho$ 
Table 1 Grouping of subjects by questionnaire and clinical assessment

\begin{tabular}{|c|c|c|c|}
\hline $\begin{array}{l}\text { Symptom } \\
\text { group }\end{array}$ & $\begin{array}{l}\text { Results from questionnaire and clinical } \\
\text { classification }\end{array}$ & $\begin{array}{l}\text { No in } \\
\text { group }\end{array}$ & $\begin{array}{l}\text { No with positive prick test } \\
\text { to } A \text { niger }\end{array}$ \\
\hline $\begin{array}{l}\text { A } \\
\text { B } \\
\text { C } \\
\text { D } \\
\text { E }\end{array}$ & $\begin{array}{l}\text { No symptoms } \\
\text { Respiratory symptoms, but not chest tightness, wheeze, } \\
\text { or asthma } \\
\text { Complained of chest tightness, wheeze, or asthma but not } \\
\text { occupational, or not clinically important } \\
\text { Complained of chest tightness, wheeze, or asthma but } \\
\text { clinically not bronchospasm (probably direct irritation) } \\
\text { Questionnaire and clinical assessment indicated } \\
\text { occupationally related bronchospasm (asthma) } \\
\text { Total }\end{array}$ & $\begin{array}{r}201 \\
36 \\
64 \\
24 \\
18 \\
343\end{array}$ & $\begin{array}{l}7(3 \cdot 5 \%) \\
0 \\
2(3 \cdot 1 \%) \\
0 \\
8(44 \%) \\
17(5 \cdot 0 \%)\end{array}$ \\
\hline
\end{tabular}

Table 1 summarises these findings. None of the 343 subjects gave a clinical history suggestive of extrinsic allergic alveolitis.

\section{RELATION BETWEEN CLINICAL ASSESSMENT AND SKIN PRICK TESTS}

The skin prick tests were performed at the same time as the questionnaire was administered. The interpretation of the questionnaires and the clinical

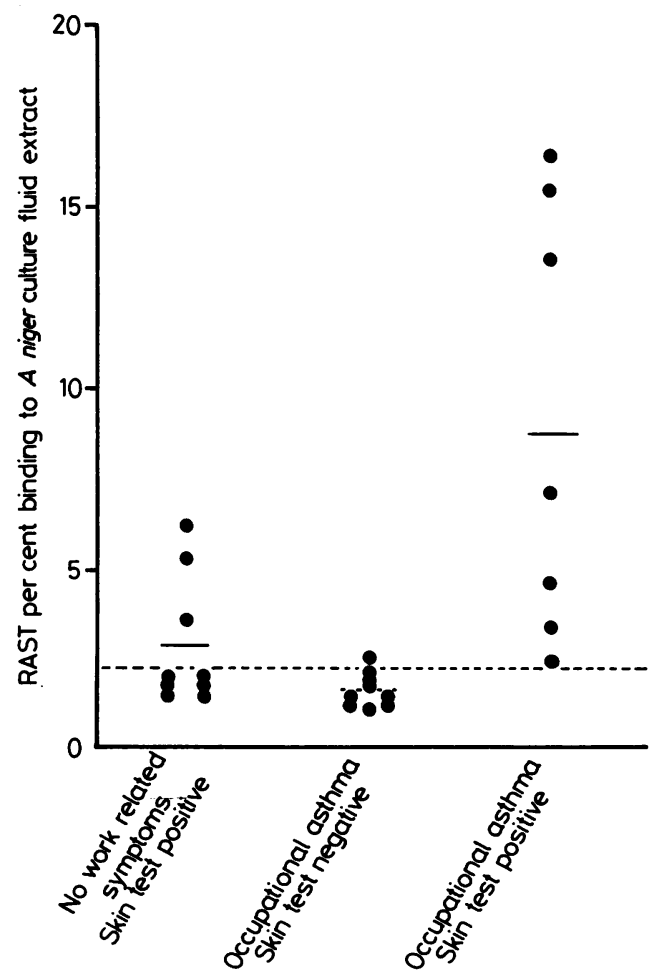

Fig 1 Specific IgE levels to A niger culture fuid extract for subjects with occupational bronchospasm and subjects without work related symptoms but with positive skin tests to $A$ niger culture fuid extract. assessments of the workers, however, were made without knowledge of the skin test results. Table 1 shows the relation between symptoms and positive skin prick tests to the $A$ niger culture fluid. Of the 325 subjects without occupational asthma (groups A-D), nine $(2.8 \%)$ had a positive prick test, whereas of the 18 subjects with occupational asthma, eight ( $44 \%)$ were prick test positive; this difference in frequency of positive prick tests is highly statistically significant, $\chi^{2}=54.3, p<0.001$.

\section{MEASUREMENT OF SPECIFIC IGE TO A NIGER CULTURE FLUID EXTRACT; RELATION WITH SYMPTOMS}

The presence of specific IgE antibodies to $A$ niger culture fluid extract was sought in all the subjects judged to have occupationally related respiratory symptoms (groups D and E) and in the subjects in the other groups who were skin test positive. Tests were also performed on a control group that was matched with the test subjects for duration of employment, smoking, and area of work (factory, office, or laboratory).

The mean RAST per cent binding to the $A$ niger culture fluid extract for the control group was $1.75 \%$, standard deviation (SD) 0.26 ; for the subjects in group D, the mean RAST per cent binding was $1.65 \%$, SD $0 \cdot 20$. On the basis of the results from the control group, a positive RAST was defined as per cent binding to the $A$ niger culture fluid extract discs of $2.25 \%$ or greater (mean for control group $+2 \mathrm{SD}$ ). Figure 1 shows the RAST results for the subjects with occupational asthma or with a positive skin test. It is noticeable that all but one of the subjects with occupational asthma who were skin test negative were RAST negative whereas all those with a positive skin test were RAST positive.

OCCUPATIONAL ASTHMA SUBJECTS, RELATION

BETWEEN SEVERITY OF SYMPTOMS, AREA OF

WORK, AND IMMUNOLOGICAL STATE

The individuals with occupational asthma (group E) 
Table 2 Subjects with occupational allergy. Comparison by area of work, severity of symptoms, and immunological state

\begin{tabular}{|c|c|c|c|c|c|c|c|c|c|}
\hline \multirow[t]{2}{*}{ Subject } & \multirow[t]{2}{*}{ Area of Work } & \multirow{2}{*}{$\begin{array}{l}\text { Severity of } \\
\text { symptoms }\end{array}$} & \multicolumn{2}{|c|}{ Skin test (sq mm) } & \multirow[b]{2}{*}{$\begin{array}{l}\text { Bencard } \\
\text { A fumigatus }\end{array}$} & \multicolumn{2}{|c|}{$R A S T$ (\% binding) } & \multirow[b]{2}{*}{$\begin{array}{l}\text { Bencard } \\
\text { A fumigatus }\end{array}$} & \multirow[b]{2}{*}{$\begin{array}{l}\text { Filter } \\
\text { extract }\end{array}$} \\
\hline & & & $\begin{array}{l}\text { A niger } \\
\text { culture } \\
\text { fuid }\end{array}$ & $\begin{array}{l}\text { Bencard } \\
\text { A niger }\end{array}$ & & $\begin{array}{l}\text { A niger } \\
\text { culture } \\
\text { fuid }\end{array}$ & $\begin{array}{l}\text { Bencard } \\
\text { A niger }\end{array}$ & & \\
\hline $\begin{array}{l}1 \\
2 \\
3 \\
4 \\
5 \\
6\end{array}$ & $\begin{array}{l}\text { Surface fermentation } \\
\text { Surface fermentation } \\
\text { Surface fermentation } \\
\text { Surface fermentation } \\
\text { Surface fermentation } \\
\text { Surface fermentation }\end{array}$ & $\begin{array}{l}++ \\
++ \\
++ \\
+ \\
+ \\
+\end{array}$ & $\begin{array}{c}25 \\
9 \\
-v e \\
9 \\
-v e \\
-v e\end{array}$ & $\begin{array}{l}30 \\
9 \\
-v e \\
-v e \\
-v e \\
-v e\end{array}$ & $\begin{array}{l}4 \\
\text {-ve } \\
-v e \\
-v e \\
-v e \\
-v e\end{array}$ & $\begin{array}{r}13 \cdot 5 \\
3 \cdot 3 \\
1 \cdot 6 \\
2 \cdot 5 \\
1 \cdot 4 \\
2 \cdot 2\end{array}$ & $\begin{array}{l}10 \cdot 3 \\
2 \cdot 3 \\
\text { NT } \\
1.9 \\
\text { NT } \\
\text { NT }\end{array}$ & $\begin{array}{l}5 \cdot 4 \\
1 \cdot 5 \\
\text { NT } \\
1 \cdot 5 \\
\text { NT } \\
\text { NT }\end{array}$ & $\begin{array}{r}3 \cdot 8 \\
1 \cdot 1 \\
0 \cdot 9 \\
1 \cdot 3 \\
1 \cdot 1 \\
\text { NT }\end{array}$ \\
\hline $\begin{array}{r}7 \\
8 \\
9 \\
10 \\
11 \\
12\end{array}$ & $\begin{array}{l}\text { Recovery } \\
\text { Recovery } \\
\text { Recovery } \\
\text { Recovery } \\
\text { Recovery } \\
\text { Recovery }\end{array}$ & $\begin{array}{l}+++ \\
++ \\
+ \\
+ \\
\pm \\
\pm\end{array}$ & $\begin{array}{l}12 \\
-v e \\
-v e \\
-v e \\
-v e \\
-v e\end{array}$ & $\begin{array}{l}\text {-ve } \\
\text {-ve } \\
\text {-ve } \\
\text {-ve } \\
\text {-ve } \\
\text {-ve }\end{array}$ & $\begin{array}{l}\text {-ve } \\
\text {-ve } \\
\text {-ve } \\
\text {-ve } \\
\text {-ve } \\
\text {-ve }\end{array}$ & $\begin{array}{l}7 \cdot 1 \\
1 \cdot 2 \\
2 \cdot 0 \\
1 \cdot 8 \\
2 \cdot 5 \\
1 \cdot 4\end{array}$ & $\begin{array}{l}6.9 \\
\text { NT } \\
\text { NT } \\
\text { NT } \\
1 \cdot 5 \\
\text { NT }\end{array}$ & $\begin{array}{l}1 \cdot 5 \\
\text { NT } \\
\text { NT } \\
\text { NT } \\
\text { NT }\end{array}$ & $\begin{array}{r}13 \cdot 6 \\
1.0 \\
0.9 \\
0.9 \\
1 \cdot 3 \\
1.4\end{array}$ \\
\hline $\begin{array}{l}13 \\
14\end{array}$ & $\begin{array}{l}\text { Laboratory and new } \\
\text { development }\end{array}$ & $\begin{array}{l}+ \\
+\end{array}$ & $\begin{array}{c}-\mathrm{ve} \\
9\end{array}$ & $\begin{array}{c}-\mathrm{ve} \\
9\end{array}$ & $\begin{array}{l}\text {-ve } \\
\text {-ve }\end{array}$ & $\begin{array}{l}1 \cdot 5 \\
4 \cdot 6\end{array}$ & $\underset{3 \cdot 8}{\text { NT }}$ & $\begin{array}{l}\text { NT } \\
1.9\end{array}$ & $\stackrel{1 \cdot 1}{\mathrm{NT}}$ \\
\hline 15 & $\begin{array}{l}\text { Citric acid drying and } \\
\text { packing }\end{array}$ & ++ & 4 & 4 & 9 & NT & NT & NT & NT \\
\hline $\begin{array}{l}16 \\
17 \\
18\end{array}$ & $\begin{array}{l}\text { All areas } \\
\text { All areas } \\
\text { All areas }\end{array}$ & $\begin{array}{l}++ \\
++ \\
+\end{array}$ & $\begin{array}{l}35 \\
49 \\
-v e\end{array}$ & $\begin{array}{c}16 \\
9 \\
-v e\end{array}$ & $\begin{array}{l}9 \\
4 \\
-v e\end{array}$ & $\begin{array}{r}15 \cdot 4 \\
16 \cdot 3 \\
1.4\end{array}$ & $\begin{array}{r}15 \cdot 8 \\
8 \cdot 7 \\
\text { NT }\end{array}$ & $\begin{array}{r}16 \cdot 5 \\
8 \cdot 6 \\
\text { NT }\end{array}$ & $\begin{array}{r}11.2 \\
3.7 \\
1.0\end{array}$ \\
\hline
\end{tabular}

NT $=$ Not tested.

$+++=$ Index case: disabling illness, change of job.

$++=$ Condition requiring medical investigation or treatment, or both.

$+=$ Less severe condition, no specific treatment.

$\pm=$ Borderline cases, suggestive history.

were grouped by severity of symptoms on the basis of time lost from work and the need for medical advice and treatment, and also by predominant place of work-that is, the area of the factory associated with the development of their symptoms. For this purpose the premises were divided into the following sections: surface fermentation, recovery, laboratory and new development area, and "all areas" (where personnel worked in all sections and could not relate their symptoms to any one particular area). Table 2 shows a comparison of severity of symptoms, by area of work, and immunological reactivity.

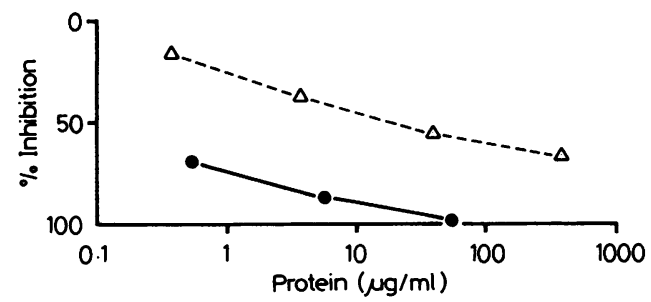

Fig 2 RAST inhibition of A niger culture fuid extract allergen discs with: (a) A niger culture fuid extract $\bigcirc$ (b) $B$ encard $A$ niger prick test extract $\triangle$. Inhibitions compared on basis of protein content of material.
It may be seen that the index case (No 7, table 2) had the most severe symptoms and that there were seven individuals whose condition was of moderate severity, warranting medical investigation or treatment, or both. It may also be seen that there were equal numbers of cases in the surface fermentation and recovery areas, but of those in the surface fermentation area, three had positive skin tests and RAST compared with one with positive skin test and RAST and one with positive RAST only in the recovery area.

The immunological reactivity of the subjects was investigated by testing those with positive RAST to the $A$ niger culture fluid with commercially available $A$ niger and $A$ fumigatus extracts. All the sera, except one, gave lower RAST binding with these extracts than the $A$ niger culture fluid extract. The $N$ remaining serum gave similar responses to each (table 2). To determine whether the difference in 0 reactivity seen with the majority of sera was due to $\omega$ concentration differences between the extracts, or $\bar{O}$ the presence of different antigenic determinants, 0 RAST inhibition experiments were performed.

\section{RAST INHIBITION}

RAST inhibition was performed with sera from two sensitised subjects (Nos 1 and 17, table 2). In the first experiment $\boldsymbol{A}$ niger culture fluid extract allergen 


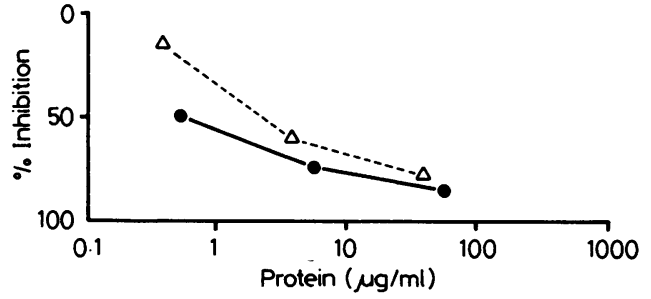

Fig 3 RAST inhibition of Bencard A niger prick test extract allergen discs with: (a) A niger culture fuid extract (b) Bencard A niger prick test extract $\triangle$. Inhibitions compared on basis of protein content of material.

discs were inhibited by $A$ niger culture fluid extract and by Bencard $A$ niger extract. When the inhibitory capacity was compared on a protein concentration basis it was apparent that the Bencard extract was much less antigenic than the culture fluid extract. Essentially the same results were obtained with both sera, and the results from one (No 17) are shown in fig 2. This difference, however, in antigenic potency was not seen when the extracts were used to inhibit binding to Bencard $A$ niger allergen discs (fig 3 ). These results suggest that the Bencard extract lacks antigenic determinants present in the culture fluid extract.

\section{DETECTION OF AIRBORNE ANTIGEN DERIVED FROM A NIGER}

The finding of subjects with occupational asthma to $A$ niger among workers in the fermentation area was not surprising since $A$ niger spores were almost certainly present in the atmosphere during the charging and emptying of the fermentation cells. The finding of sensitisation to $A$ niger among workers in the recovery area was more difficult to explain since there was no possibility of $A$ niger spores being present in that area. Nevertheless, the counter current

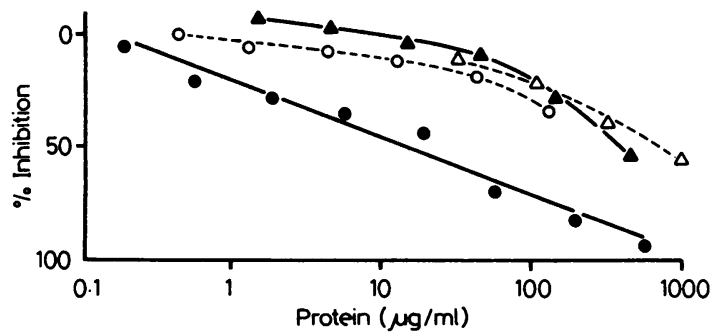

Fig 4 RAST inhibition of A niger culture fluid extract allergen discs with: (a) A niger culture fluid extract $\bullet$ (b) extract from counter current washing water $\Delta(c)$ filter $A$ extract $\Delta(d)$ filter $B$ extract $\bigcirc$. Inhibitions compared on basis of protein content of material. washing procedure generated a significant amount of aerosol; consequently to determine whether $\boldsymbol{A}$ niger antigen derived from the culture was becoming airborne, air samples were taken. Two Staplex samplers were fitted with fibreglass filters and run for 17 hours at $1600 \mathrm{l} / \mathrm{min}$. The total dry weight of material collected on the filters was $1171 \mathrm{mg}$ for filter $\mathrm{A}$ and $148.6 \mathrm{mg}$ for filter $\mathrm{B}$, giving airborne concentrations of particulate material of 708 and $89 \mu \mathrm{g} / \mathrm{m}^{3}$ respectively.

Antigen was then extracted from the filter and used in RAST inhibition experiments. In addition an extract was prepared from the wash water, taking a sample at the final spray nozzle, at which point the water has already been through the calcium citrate slurry twice. The abilities of the $\boldsymbol{A}$ niger culture fluid extract, the wash water extract, and the filter extracts to inhibit the $\boldsymbol{A}$ niger culture fluid extract allergen discs were compared on a protein concentration basis. From the results (fig 4) it was apparent that airborne $A$ niger antigen was present in the recovery area since significant inhibition was observed with both the filter extracts. The finding that the wash water also contained appreciable amounts of $\boldsymbol{A}$ niger antigen suggests that the spraying of the wash water was a potential source of airborne antigen.

Since nine of the subjects with occupational asthma did not have a positive RAST or skin prick test to the culture fluid extract, the upper level filter extract was used in a direct RAST to ascertain whether these subjects had specific IgE to airborne antigen not derived from the $A$ niger culture fluid. The results (table 2, right-hand column) showed that this was not the case. Nevertheless, the finding of positive RAST to the filter extracts in subjects with specific IgE to the culture fluid provided further confirmation of the presence of airborne antigen.

\section{Discussion}

In a survey of 343 workers employed at a factory which used $A$ niger in a fermentation process 18 (4.9\%) were identified as having occupational asthma. The diagnosis was made by means of the MRC respiratory questionnaire followed by clinical assessment of all subjects who reported chest tightness, wheeze, or asthma. The questionnaire, which was administered by suitably trained clerical staff, identified symptomatic subjects, and therefore made best use of medically qualified personnel in that their time was not spent interviewing asymptomatic subjects. Clinical assessment was found to be necessary to enable a judgment to be made as to whether or not symptoms were work related and to enable a clinical diagnosis of occupational asthma to be 
made. Further confirmation of symptoms by pulmonary function tests was not sought, partly because of the large numbers of subjects potentially affected and because, in several cases, the diagnosis of asthma was made on the history of past incidents. Current pulmonary function measurements would have given no information about these. Evidence of sensitisation to antigens present in the factory environment was obtained by means of skin prick tests and RAST.

From the 18 subjects clinically diagnosed as having occupational bronchospasm, sensitisation to $A$ niger was confirmed by RAST or skin prick test, or both, in nine. Whereas, in the absence of bronchial challenge tests, it is not possible to provide unequivocal evidence that the symptoms in these nine subjects were due to $A$ niger, the low level of sensitisation in asymptomatic subjects strongly implicates $A$ niger as the causative agent. In the nine other subjects the diagnosis of occupational bronchospasm was not associated with sensitisation to $A$ niger, as measured by skin prick test and RAST. Attempts to demonstrate sensitisation to other airborne antigens by using an extract of a filter from an air sampler in a direct RAST were unsuccessful. Thus either these subjects were sensitised to $A$ niger but lacked circulating specific IgE or they were sensitised to an agent we were unable to identify.

Fungal extracts are complex mixtures of proteins; A fumigatus, Cladosporium herbarum, and Alternaria alternata, for example, have been shown to contain up to 60 different antigens. ${ }^{12}$ Furthermore, Wallenbeck $e$ al found that 10 different strains of $A$ fumigatus showed considerable antigenic variation. ${ }^{13}$ Thus the finding by RAST inhibition of qualitative differences between the $A$ niger culture fluid extract and a commercially available extract is not unexpected, and emphasises the importance in this type of investigation of preparing antigen extracts from the strain of micro-organisms used at the factory.

In addition to variations in antigenic composition, it has been shown for $\boldsymbol{A}$ fumigatus that subjects may respond differently to the various antigenic components in an extract. ${ }^{13}$ In the present study fractionation of the antigenic components was not carried out. Thus we have no information as to whether the subjects are responding to the same allergens. The finding that one subject gave much higher response to the filter extracts than the culture fluid extract (table 2), however, suggests heterogeneity in response. Since a purified major $\boldsymbol{A}$ niger allergen was not available, no attempt was made to determine quantitatively the amount of $\boldsymbol{A}$ niger antigen collected by the air samplers. The aim of the RAST inhibition experiments was merely to determine whether or not $\boldsymbol{A}$ niger antigen was becoming air- borne.

The demonstration, by RAST inhibition, that the $\stackrel{\mathbb{Q}}{?}$ counter current washing water contained significant $\vec{F}$ amounts of $A$ niger antigen, suggested that the $\stackrel{\mathcal{O}}{+}$ spraying of this water was responsible for the generation of the airborne antigen detected by air sampling. The similar antigenic potency, on a protein con- $\frac{\bar{D}}{\bar{D}}$ centration basis, of the wash water and the filter $\stackrel{\mathbb{Q}}{\complement}$ extracts from the air samplers provided further sup- i port for this suggestion (fig 4). As a result of this $\vec{\circ}$ finding recommendations on hygiene methods available for controlling the aerosol generated by the $\vec{\omega}$ washing procedure have been made to the firm.

Finally, this investigation shows that workers in $\stackrel{\mathbb{D}}{\triangle}$ this type of industry are at risk from sensitisation not only to fungal spores, but also to protein in an $\hat{N}$ aerosol of culture fluid, and emphasises the need for or careful hygiene control at each stage of the process. $\frac{\omega}{N}$

We thank the employees and management at the $\stackrel{\circ}{工}$ firm for their cooperation, Mr M Griffiths (FI9, $\vec{\sim}$ HSE) and Mr P Davies (aerobiology unit, Brompton Hospital) for running the atmospheric samplers, and Mr H Mason (biochemistry section, HSE) for performing the protein analyses.

\section{References}

' Phaff HJ. Industrial micro-organisms. Sci Am 1981;235:76-89.

${ }^{2}$ Darke CS, Knowelden J, Lacey J, Milford Ward A. Respiratory $\vec{F}$ disease of workers harvesting grain. Thorax 1976;31:294-302.윽

${ }^{3}$ Klaustermeyer WB, Bardana EJ, Hale FC. Pulmonary hypersen-

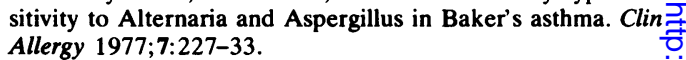

${ }^{4}$ Parkes WR. Occupational asthma (including byssinosis). In: Occupational lung disorders. London: Butterworths, 1982:415-53.

5 Metha SK, Sandhu RS. Immunological significance of Aó fumigatus in cane sugar mills. Arch Environ Health 1983;38:41-6.

${ }^{6}$ Mullins J, Seaton A. Fungal spores in lung and sputum. Clin Allergy 1978;8:525-33.

' Metzger JB, Garagnsi VF, Kerwin DM. Pulmonary oxalosisO caused by Aspergillus niger. Am Rev Respir Dis 1984; 129:501-2.

${ }^{8}$ Moore RS, Hastin PS, Lawson RAM, Stanbridge TN. Aspergillus niger endocarditis complicating aortic tissue valve replace- $N$ ment. Thorax 1984;39:76-7.

${ }^{9}$ Bradford MM. A rapid and sensitive method for the quantitationn of microgram quantities of protein utilising the principle of protein dye binding. Anal Biochem 1976;72:248-52.

${ }^{10}$ Ceska M, Eriksson R, Vargo JM. Radio-immunosorbent assay of allergens. J Allergy Clin Immunol 1972;49:1-7.

" Yman L, Ponterius G, Brandt R. RAST-based allergen assayC methods. Developments in Biological Standardisation 1975; 29: 151-65.

${ }^{12}$ Salvaggio J, Aukrust L. Mould induced asthma. J Allergy Clin Immunol 1981;68:327-46.

${ }^{13}$ Wallenbeck I, Aukrust L, Einarsson R. Antigenic variability of different strains of A fumigatus. Int Arch Allergy Appl Immunol 1984;73:166-72. 